\title{
The effects of feeding a partial mixed ration plus a top-dress before feeding on milk production and the daily rhythm of feed intake and plasma hormones and metabolites in dairy cows
}

\author{
M. Niu ${ }^{1}$ and K. J. Harvatine ${ }^{2}$ \\ Department of Animal Science, Penn State University, University Park 16802
}

\begin{abstract}
Total mixed rations (TMR) are commonly fed to dairy cows with a goal of reducing ruminal acidosis, but the daily pattern of feed intake has major implication for rumen fermentation and postabsorptive physiology. Generally there is low feed intake during the overnight period and high intake after feeding and during the afternoon. The objective of this study was to determine if feeding a partial mixed ration (PMR) plus a high starch top-dress before feeding of the PMR would improve production and modify key daily rhythms. The top-dress was fed before feeding as ruminal starch is at a nadir and amylolytic capacity is expected to be low. Ten Holstein cows were used in a crossover design with 14-d periods. Cows were housed in tie stalls with feed tubs and feed weight was recorded every $10 \mathrm{~s}$ for observation of feeding behavior. Treatments were a control TMR fed once per day at $0900 \mathrm{~h}$ or a partial mixed ration plus a top-dress (PMR+TD). The top-dress was fed at $9.5 \%$ of DMI offered at $0800 \mathrm{~h}$ and contained steamflaked corn, canola meal, and nonprotein nitrogen. No interaction was observed between treatment and milking time. Milk yield tended to be decreased $1.1 \mathrm{~kg}$ and milk fat yield was decreased 70 $\mathrm{g} / \mathrm{d}$ by PMR+TD. Milk fat preformed fatty acids were decreased and no effect was observed of treatment on trans-10 C18:1 or other indicators of biohydrogenationinduced milk fat depression. No effect was observed of treatment on meal parameters including meal size and number. The PMR+TD increased total-tract neutral detergent fiber (NDF) digestibility by 1.2 percentage points. Treatment changed the daily pattern of fecal $\mathrm{NDF}$ and indigestible NDF, indicating changes in rumen function over the day. No effect was observed on plasma glucose, but the amplitude of the daily rhythm
\end{abstract}

\footnotetext{
Received July 11, 2017.

Accepted September 17, 2017.

${ }^{1}$ Current address: Farmers Business Network, San Carlos, CA 94070.

${ }^{2}$ Corresponding author: kjh182@psu.edu
}

of insulin was increased by PMR+TD. The PMR+TD also increased plasma nonesterified fatty acids and decreased blood urea nitrogen across the day. Core body temperature is entrained by the central biological clock and its phase was advanced 42 min and its amplitude slightly increased by PMR+TD. In conclusion, the topdress appears to have modified the central circadian rhythm and plasma insulin and blood urea nitrogen. This demonstrates that timing of feeding can be used to manage daily rhythms of the dairy cow, although the optimal timing requires further investigation.

Key words: circadian, diurnal, partial mixed ration, total mixed ration

\section{INTRODUCTION}

Total mixed rations are commonly fed to modern dairy cows, but a daily pattern of feed intake results in over a 3 -fold change in the rate of fermentable substrate entering the rumen over the day (Niu et al., 2014, 2017). Additionally, cows within a herd or group differ in their nutrient needs, making balancing a single TMR for all cows difficult. Supplementation with a high starch topdress may be advantageous and feasible in some situations such as tie-stalls, robotic feeding, and groups on small dairies mixing a single batch of TMR. However, the optimal timing of the supplementation is not clear.

Most physiological processes follow a circadian rhythm entrained by the light-dark cycles and other environmental cues including feed availability (see review Schibler et al., 2003). Plasma cortisol, growth hormone, insulin, nonesterified fatty acids (NEFA), BUN, locomotor activity, and body temperature have been reported to follow a circadian rhythm in the dairy cow (Lefcourt et al., 1995, 1999; Giannetto and Picciano, 2009). We recently have reported circadian rhythms in feed intake and milk synthesis (Niu et al., 2014; Rottman et al., 2014).

Generally, feed intake is low overnight, increases drastically after fresh feed delivery, and is higher in during the afternoon and early evening with TMR feeding (e.g., DeVries et al., 2005). This daily pattern 
has an effect on rumen digesta composition and the ruminal starch pool is lowest in the morning because of low intake during the night and the high rate of starch digestion. Additionally, lower ruminal amylolytic capacity before feeding compared with after feeding has been reported (Fickett and Allen, 2002). Because rumen starch pool and amylolytic capacity are lowest in the morning before TMR delivery, we proposed that this might be an optimal time to provide a high-starch supplement, as it would decrease starch intake during the high-intake period of the day. Supplementation strategies have been well investigated in the context of pasture (Auldist et al., 2016), component feeding (Auldist et al., 2016), and robotic milking (Bach and Cabrera, 2017), but timing supplementation relative to rumen dynamics has not been well investigated. The hypothesis was that feeding a high starch top-dress in the morning would decrease peak starch intake during the afternoon and modify daily rhythms of plasma metabolites and hormones.

\section{MATERIALS AND METHODS}

\section{Experimental Design and Treatments}

The experiment was conducted at the Pennsylvania State University Dairy Production Research and Teaching Center. Twelve noncannulated multiparous Holstein cows $(2.5 \pm 0.69$ parities; $163 \pm 35.8$ DIM; mean \pm $\mathrm{SD})$ were housed in a tie-stall barn with mattresses and sawdust bedding and randomly assigned to treatment sequences in a crossover design with 14-d periods, but 2 cows were removed from data analysis as they refused to consume more than $10 \%$ of the top-dress. Rations were a TMR or a partial mixed ration (PMR) with a top-dress fed a $9.5 \%$ of DMI fed at $0800 \mathrm{~h} \mathrm{(1}$ $\mathrm{h}$ before the feeding of PMR; Table 1). The top-dress contained steamflaked corn, canola meal, and NPN and was balanced to be isonitrogenous with the TMR. The TMR delivered the same nutrient composition as the PMR plus the top-dress. Cows were individually fed the TMR and PMR ad libitum at $110 \%$ of expected daily intake. A light-sensing data logger verified a consistent $18 \mathrm{~h}$ light to $6 \mathrm{~h}$ of dark schedule (dark $\sim 2300$ to 0500 h).

\section{Data and Sample Collection and Analysis}

Nine cows were housed in tie stalls equipped with a feed intake observation system using feed tubs hanging from load cells as described by Niu et al. (2014). Briefly, feed weight was recorded every $10 \mathrm{~s}$ from d 15 to 21 of each period. Feed intake over 2-h intervals over the day was calculated based on running averages. Meals were determined through a multi-step process as described by Niu et al. (2017).

Each ration and individual feed ingredients were sampled on d 8, 11, and 14 and orts $(12.5 \%)$ were sampled before the morning feeding from d 8 to 14 of each period. Feed and orts samples were composited by period. Forages and a mix of concentrate feeds representing what was mixed were analyzed for DM, NDF, indigestible NDF (iNDF; $240 \mathrm{~h}$ in vitro), CP, and ash by wet chemistry procedures (Cumberland Valley Analytical Services Inc., Hagerstown, MD) and starch concentration by an enzymatic method according to Karkalas (1985). Orts samples were analyzed for DM, NDF, and ash by the same procedures.

Cows were milked twice daily at 0500 and $1700 \mathrm{~h}$, and milk yield was determined by an integrated milk meter (AfiMilk; SAE Afikim, Israel) and analyzed as the average of d 12, 13, and 14 of each period. Milk

Table 1. Ingredients and chemical composition of treatment diets ${ }^{1}$

\begin{tabular}{lccc}
\hline Item & TMR & PMR & Top-dress \\
\hline Ingredient, \% of DM $^{\text {Corn silage }}$ 2 & & & \\
Alfalfa haylage $^{3}$ & 34.4 & 38.0 & - \\
Grass hay $_{\text {Ground corn }}$ & 22.9 & 25.2 & - \\
Steam-flaked corn $^{4}$ & 3.57 & 3.95 & - \\
Canola meal & 7.25 & 8.03 & - \\
Soybean roasted & 7.80 & - & 81.9 \\
Bakery byproduct & 6.61 & 5.48 & 17.4 \\
Molasses & 7.28 & 8.05 & - \\
Vitamin-mineral mix & \\
NPN & 3.66 & 4.05 & - \\
Chemical composition, $\%$ & 3.21 & 3.56 & - \\
of DM & 3.04 & 3.36 & - \\
DM & 0.32 & 0.29 & 0.66 \\
NDF & & & \\
ADF & 52.0 & 49.8 & 89.4 \\
CP & 32.2 & 34.7 & 10.7 \\
Starch & 20.9 & 21.5 & 7.0 \\
Ash & 16.6 & 16.6 & 15.4 \\
\end{tabular}

${ }^{1}$ Treatments were a TMR or a partial mixed ration (PMR) and a topdress fed at $9.5 \%$ of daily DMI.

${ }^{2}$ Contained $34 \% \mathrm{DM}$ and $8.9 \% \mathrm{CP}, 39.2 \% \mathrm{NDF}$, and $30.6 \%$ starch on a DM basis.

${ }^{3}$ Contained $54 \% \mathrm{DM}$ and $19.2 \% \mathrm{CP}, 49.3 \% \mathrm{NDF}$, and $1.1 \%$ starch on a DM basis.

${ }^{4}$ Contained $89 \%$ DM and $74.9 \%$ starch on a DM basis. Seven-hour starch digestibility of $69.8 \%$ (Pennfield Feeds, Mount Joy, PA).

${ }^{5}$ Contained (\%, as-fed basis): 45.8 dried corn distillers grains with solubles; 35.8 limestone ( $38 \%$ Ca); 8.3 magnesium oxide $(54 \% \mathrm{Mg}) ; 6.4$ salt; 1.73 vitamin A, D, E premix; 1.09 selenium premix (0.06\% selenium); and 0.88 trace mineral mix. Composition (DM basis): $11 \% \mathrm{CP}$; $18 \%$ NDF; $5.2 \%$ fat; $14.9 \%$ Ca; $0.35 \%$ P; $4.58 \%$ Mg; $0.41 \% \mathrm{~K} ; 0.31 \%$ $\mathrm{S} ; 357 \mathrm{mg} / \mathrm{kg}$ of Cu; $1,085 \mathrm{mg} / \mathrm{kg}$ of Zn; $181 \mathrm{mg} / \mathrm{kg}$ of Fe; $6.67 \mathrm{mg} / \mathrm{kg}$ of Se; $125,875 \mathrm{IU} / \mathrm{kg}$ of vitamin A (retinyl acetate); 31,418 IU $/ \mathrm{kg}$ of vitamin D (activated 7-dehydrocholesterol); and $946 \mathrm{IU} / \mathrm{kg}$ of vitamin E (DL- $\alpha$-tocopheryl acetate). Purchased from Cargill Animal Nutrition (Minneapolis, MN).

${ }^{6}$ Coated urea (Optigen, Alltech Inc., Lexington, KY; $256 \%$ CP on DM basis). 
was sampled at both milkings from d 12 to 14 of each period and analyzed for fat (filter B) and true protein by infrared spectroscopy (Dairy One Lab, State College, PA). Milk fatty acid profile was determined by GC with a flame ionization detector at each milking on d 21 as described by Rico and Harvatine (2013).

Blood samples were collected on d 12 to 14 of each period (0000, 0400, 0800, 1200, 1600, and $2000 \mathrm{~h}$ ). Plasma samples were analyzed for insulin (Coat-ACount Insulin Kit, Siemens Healthcare Diagnostics, Los Angeles, CA), glucose [PGO Enzyme procedure no. P 7119, Sigma-Aldrich, St. Louis, MO], BUN [Modified Enzymatic Urea Nitrogen (Procedure No. 2050); Stanbio Laboratory, Boerne, TX], and NEFA [Wako HR Series NEFA-HR kit (Wako Chemicals USA Inc., Richmond, VA) as modified by Ballou et al. (2009)].

Fecal grab samples were also collected at the same time as blood sampling and fecal NDF and iNDF (240 $\mathrm{h}$ in vitro) were measured on all samples (Cumberland Valley Analytical Services Inc.). Total-tract digestibility was determined using iNDF as an internal marker.

Core body temperature was recorded every $10 \mathrm{~min}$ from d 15 to 21 of each period using an intra-vaginal temperature probe (iBCod, Alpha Mach Inc., MontSt.-Hilaire, QC, Canada) as previously described (Niu et al., 2014).

\section{Statistical Analysis}

Feeding behavior, plasma metabolites and hormones, body temperature, lying activity, and fecal NDF and iNDF concentration were statistically analyzed using the MIXED procedure of SAS with repeated measures (version 9.3, SAS Institute Inc., Cary, NC). The model included the random effects of sequence, period, and cow nested in sequence and the fixed effect of treatment, time (variable depending on variable), and the interaction of treatment and time. The $\mathrm{AR}(1)$ and ARH(1) covariance structures were used based on model fit, time of day was the repeated variable, and cow by treatment was the subject. The preplanned contrasts tested the effect of treatment at each time point and denominator degrees of freedom were adjusted by the Kenward-Roger method. Parameters averaged over the day were analyzed with a reduced model that did not include the effect of time using JMP (version 9.4, SAS Institute Inc.). Significance was declared at $P<$ 0.05 and $P<0.10$ for main effects and interactions, respectively, and tendencies at $P<0.10$ and $P<0.15$ for main effects and interactions, respectively.

Second, time course data were then fit to a cosine function with a 24 -h period for circadian rhythm analysis using the linear form of the cosine function in Proc Mixed as described by Niu et al. (2014). A zero ampli- tude $F$-test comparing the cosine fit to a linear fit was used to determine the significance of fit for each treatment. The preplanned contrasts tested the differences in amplitude and acrophase (report as time at peak).

\section{RESULTS AND DISCUSSION}

The top-dress was palatable to 10 of the 12 cows enrolled in the experiment who consumed $99 \pm 2.3 \%$ (mean $\pm \mathrm{SD}$ ) of the top-dress during the allowed time. Two cows refused to consume the top-dress during the entire experiment and were not included in the analysis. The basis for this refusal is not clear, but may have been a specific taste aversion or may have been due to the fact that the cows had not been fed a concentrate alone since weaning and may have required specific training.

\section{Milk Production and Milk Fatty Acids}

Milk yield and composition were observed at both milkings per day, but no interaction between milking time and treatment were observed, so data were analyzed by day. Rottman et al. (2014) observed an interaction of timing of feed intake and milk synthesis over the day in cows fed once per day compared with 4 times per day. The supplement in the current experiment may have resulted in less difference in intake over the day or the length and timing of the 12-h milking interval may have precluded observation of an interaction.

Milk yield tended to be decreased $1.1 \mathrm{~kg} / \mathrm{d}$ by PMR+TD (Table 2). Rottman et al. (2014) investigated the effect of feeding 2 rations differing in starch concentration at different times within a day in an attempt to complement the daily pattern of intake and stabilize rumen fermentation. Feeding a high-starch diet in the morning increased milk fat yield compared with feeding the low-forage diet at night, presumably because of a priming effect allowing a more rapid increase in rumen starch from the low levels during the overnight period. However, using a similar 2 ration approach that included steam-flaked corn in the high-starch diet Niu et al. (2017) did not observe an increase in milk yield. This may indicate an interaction of timing of starch feeding and rate of starch fermentability.

Milk fat yield was decreased $70 \mathrm{~g} / \mathrm{d}$ by PMR+TD, but no effect was observed on protein yield (Table 2). No effect was observed of treatment on milk fat and protein concentration. The decrease in milk fat yield was predominantly driven by the tendency for a decrease in milk yield, but also a 0.07 percentage point numerical decrease in milk fat concentration. No change was observed in milk fat trans-10 C18:1, the main intermediate of the alternate biohydrogenation $(\mathbf{B H})$ 
Table 2. Feed intake, milk production and composition, and fatty acid (FA) profile of cows fed a partial mixed ration plus a top-dress $(\mathrm{PMR}+\mathrm{TD})$ or a control TMR

\begin{tabular}{|c|c|c|c|c|}
\hline \multirow[b]{2}{*}{ Item } & \multicolumn{2}{|c|}{ Treatment mean ${ }^{1}$} & \multirow[b]{2}{*}{$\mathrm{SE}$} & \multirow[b]{2}{*}{$P$-value ${ }^{2}$} \\
\hline & Control & $\mathrm{PMR}+\mathrm{TD}$ & & \\
\hline \multicolumn{5}{|l|}{ Yield, kg/d } \\
\hline Milk & 37.7 & 36.6 & 1.55 & 0.05 \\
\hline Fat & 1.38 & 1.31 & 0.06 & $<0.01$ \\
\hline Protein & 1.13 & 1.10 & 0.04 & 0.07 \\
\hline \multicolumn{5}{|l|}{ Milk composition, \% } \\
\hline Fat & 3.67 & 3.60 & 0.18 & 0.20 \\
\hline Protein & 3.01 & 3.03 & 0.07 & 0.47 \\
\hline \multicolumn{5}{|l|}{ Milk FA, $\%$ of FA } \\
\hline trans-10 C18:1 & 0.47 & 0.49 & 0.04 & 0.45 \\
\hline trans-11 C18:1 & 1.22 & 1.13 & 0.07 & 0.08 \\
\hline cis-9,trans-11 CLA & 0.56 & 0.53 & 0.05 & 0.11 \\
\hline trans-10,cis-12 CLA & $\mathrm{ND}^{3}$ & ND & - & - \\
\hline$\Sigma \mathrm{FA}<16 \mathrm{C}^{4}$ & 26.3 & 26.6 & 0.7 & 0.17 \\
\hline$\Sigma 16 \mathrm{C}^{4}$ & 29.6 & 29.7 & 0.8 & 0.52 \\
\hline$\Sigma \mathrm{FA}>16 \mathrm{C}^{4}$ & 37.3 & 36.8 & 0.6 & 0.04 \\
\hline
\end{tabular}

${ }^{1}$ Least squares means. Treatments were a TMR-fed control and a PMR plus a top-dress containing steam-flaked corn, canola meal, and NPN at $9.5 \%$ of DMI before feeding the PMR (PMR+TD).

${ }^{2}$ Effect of treatment.

${ }^{3} \mathrm{ND}=$ below the level of detection.

${ }^{4}$ Fatty acids $<16 \mathrm{C}$ originate from the mammary gland (C15:0 is not included); fatty acids $>16 \mathrm{C}$ originate from plasma; 16C fatty acids originate from both sources.

pathway associated with $\mathrm{BH}$-induced MFD (Harvatine et al., 2009). However, PMR+TD decreased milk fat trans-11 C18:1 from 1.22 to $1.13 \%$ of fatty acids, indicating more complete $\mathrm{BH}$ that would be normally attributed to either a change in the microbial population or an increase in rumen residence time. There was no change in de novo synthesized fatty acid ( $<16$ carbons) or mixed source fatty acid (16 carbons), but PMR+TD decreased preformed fatty acids by 0.5 percentage point. Taken together, no change in the alternate $\mathrm{BH}$ intermediate, a slight decrease in the normal BH intermediate, and no change in de novo synthesized fatty acids indicates that little to no BH-induced MFD occurred in the experiment. The decrease in milk fat yield appears to be driven by decreased preformed fatty acid, which may be due to the increased insulin after feeding in PMR+TD discussed below. Insulin can increase uptake of plasma lipids by nonmammary tissues and result in a small decrease in milk fat yield (reviewed by Harvatine et al., 2009). Niu et al. (2017) also observed decreased milk fat concentration and yield with no change in trans-10 C18:1 and no increase in insulin when feeding a high-starch PMR that contained steam-flaked corn in the morning compared with a TMR control and a low-starch PMR fed in the morning. Recently Urrutia and Harvatine (2017) reported that ruminal acetate infusion dose-dependently increased milk fat yield, opening the possibility that the decreased milk fat observed with these feeding strategies may be due to decreased acetate supply. However, PMR+TD did increase NDF digestibility as discussed below, which would be expected to increase acetate supply. However, associative effects in the rumen may have modified fermentation products.

\section{Feed Intake and Feeding Patterns}

No effect was observed of treatment on overall daily DMI, but total-tract digested NDF tended to be increased $0.2 \mathrm{~kg} / \mathrm{d}$, predominantly due to a 1.2 percentage unit increase in NDF digestibility (Table 3). Fibrolytic microbes are sensitive to decreases in $\mathrm{pH}$. Although not measured in the current experiment, shifting starch intake to the early morning when rumen starch concentration is low and rumen $\mathrm{pH}$ is high may have increased $\mathrm{pH}$ nadir or time under $\mathrm{pH}$ 5.8. No change in NDF digestibility was observed when feeding high-starch PMR in the morning in Rottman et al. (2014) and Niu et al. (2017).

There was also no effect of treatment on number of meals per day, meal size, or other meal parameters (Table 3). In addition, no difference was observed in the pattern of intake of the TMR/PMR over the day plotted as a percent of daily intake per hour, but starch intake was decreased by PMR+TD during the first interval after feeding, tended to be decreased during the afternoon, and was decreased in the late evening (Figure 1). Starch intake was slightly increased at midnight and $0400 \mathrm{~h}$ in the PMR+TD, which may indicate increased hunger due to consumption of the lower energy PMR. The top-dress was successful in decreasing

Table 3. Apparent total-tract digestibility and meal parameters of lactating cows fed a partial mixed ration plus a top-dress (PMR+TD) or a control TMR

\begin{tabular}{|c|c|c|c|c|}
\hline \multirow[b]{2}{*}{ Item } & \multicolumn{2}{|c|}{ Treatment mean $^{1}$} & \multirow[b]{2}{*}{$\mathrm{SE}$} & \multirow[b]{2}{*}{$P$-value ${ }^{2}$} \\
\hline & Control & $\mathrm{PMR}+\mathrm{TD}$ & & \\
\hline DMI, $\mathrm{kg} / \mathrm{d}$ & 26.1 & 26.7 & 0.34 & 0.16 \\
\hline $\begin{array}{l}\text { NDF } \\
\text { Dionsted } k r / d\end{array}$ & & & & \\
\hline Digested, kg/d & 3.5 & 3.7 & 0.21 & 0.05 \\
\hline Digestibility, \% & 43.9 & 45.1 & 3.51 & $<0.05$ \\
\hline Meals & & & & \\
\hline Bouts/d & 10.6 & 10.8 & 0.87 & 0.84 \\
\hline Length, $\min /$ meal & 30.9 & 30.1 & 1.82 & 0.50 \\
\hline Interval, min & 96.6 & 95.9 & 8.20 & 0.89 \\
\hline Size, kg & 2.6 & 2.5 & 0.26 & 0.47 \\
\hline Eating rate, $\mathrm{kg} / \mathrm{min}$ & 0.092 & 0.097 & 0.0110 & 0.72 \\
\hline Eating time, $\min / \mathrm{d}$ & 252 & 244 & 6.0 & 0.16 \\
\hline
\end{tabular}

${ }^{1}$ Least squares means. Treatments were a TMR-fed control and a partial mixed ration (PMR) plus a top-dress containing steam-flaked corn, canola meal, and NPN at $9.5 \%$ of DMI before feeding the PMR (PMR+TD)

${ }^{2}$ Effect of treatment. 

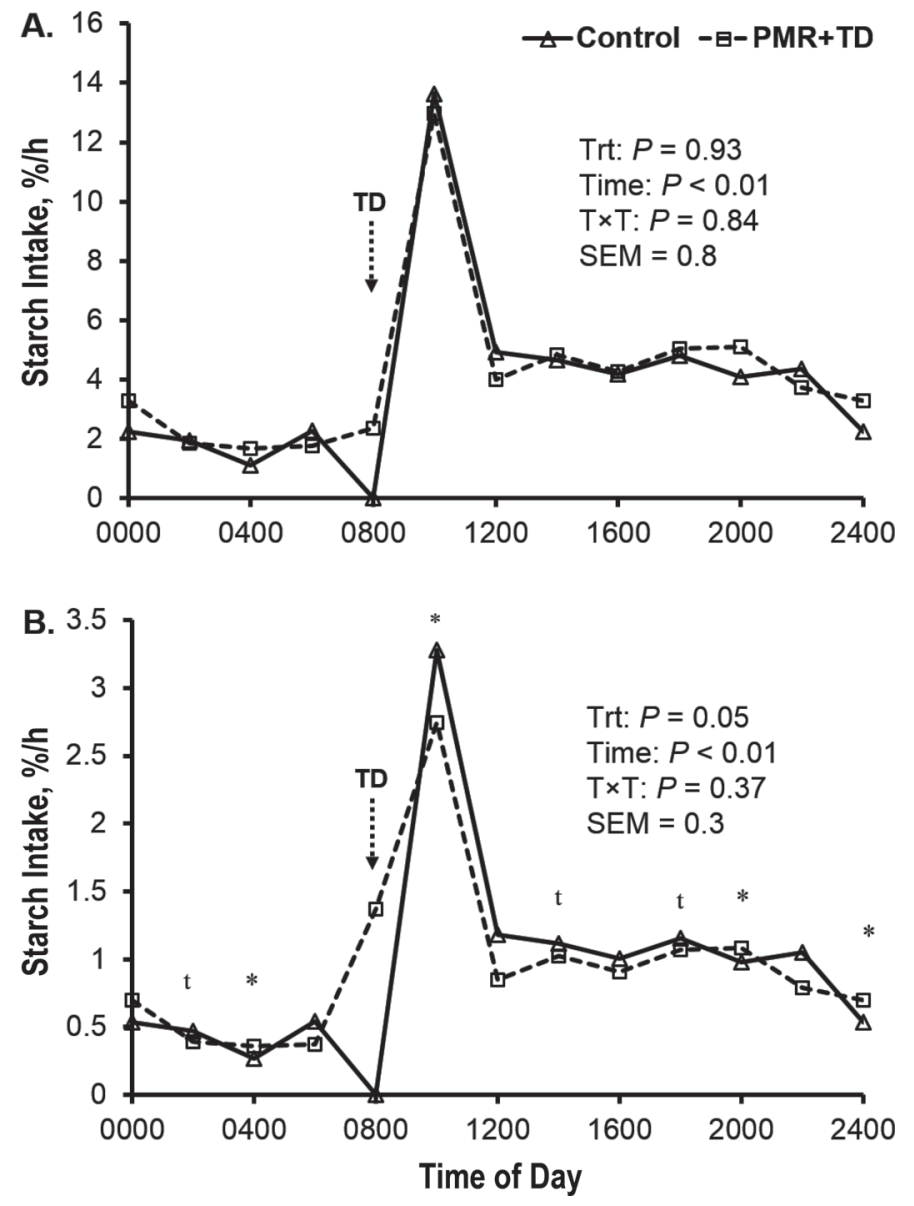

Figure 1. Daily pattern of DM and starch intake in cows fed a TMR (control) or a partial mixed ration plus a top-dress at $0800 \mathrm{~h}$ (PMR+TD). The grain mix contained steam-flaked corn, canola meal, and NPN and was fed at $9.5 \%$ of DMI. Effect of treatment (Trt), time, and their interaction $(\mathrm{T} \times \mathrm{T})$ is shown. Overall rate of starch intake $(\% / \mathrm{h})$ is higher for control than top-dress $(0.96$ vs. $0.86 \% / \mathrm{h}, P$ $=0.05)$. Differences between control and PMR + TD are shown $\left({ }^{*} P<\right.$ 0.05 and $\left.{ }^{\mathrm{t}} P<0.10\right)$.

starch intake during the high intake period of the day, but the extent is limited by the size of the top-dress. Increasing top-dress amount may result in slug feeding, but feeding multiple top-dresses would allow a greater decrease in PMR starch concentration.

Fecal NDF and iNDF follow a daily pattern that is modified by the timing of feed and nutrient intake (Niu et al., 2014, 2017) and provide a noninvasive measure of the daily pattern of rumen function. In the current experiment, fecal NDF fit a cosine function with a $24-\mathrm{h}$ period in TMR-fed cows, but not PMR+TD, possibly indicating fewer daily variations in rumen dynamics. Fecal iNDF did not fit the cosine function in either treatment. The daily pattern of fecal NDF was similar between treatments, but tended to be higher at 1200 $\mathrm{h}$ and was lower at $2200 \mathrm{~h}$ in PMR+TD than TMR
(Figure 2). Fecal iNDF was higher in PMR+TD at 0400, 1600, and $2200 \mathrm{~h}$. Little is known about what determines the daily pattern of fecal NDF and iNDF, but is likely affected by both the timing of NDF intake and changes in rumen function and passage rate. In the current experiment the changes observed may indicate changes in the dynamics of rumen fermentation and passage rate across the day. Changes in rumen passage rate may be caused by changes in the rate of VFA

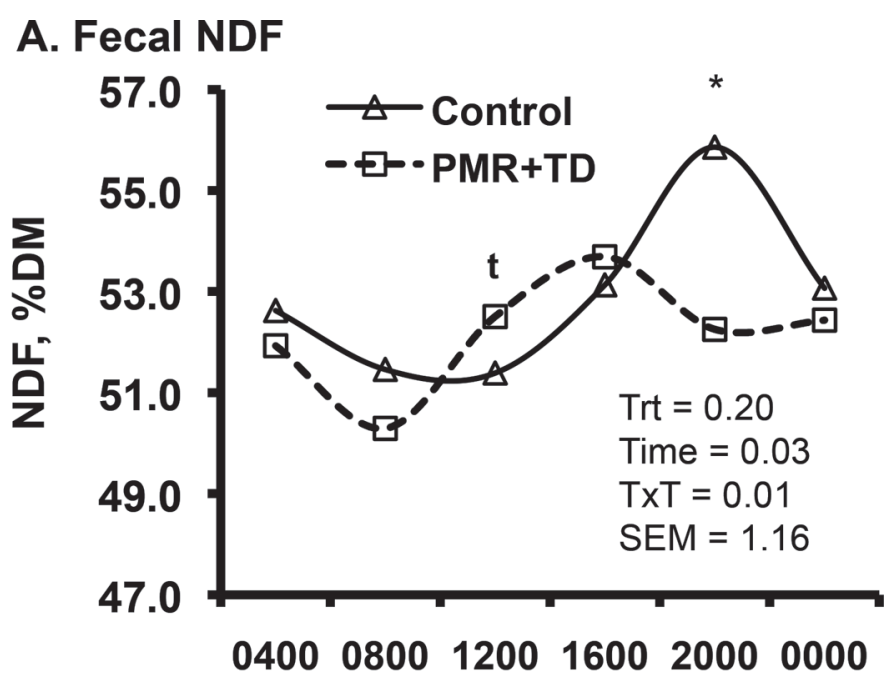

B. Fecal iNDF

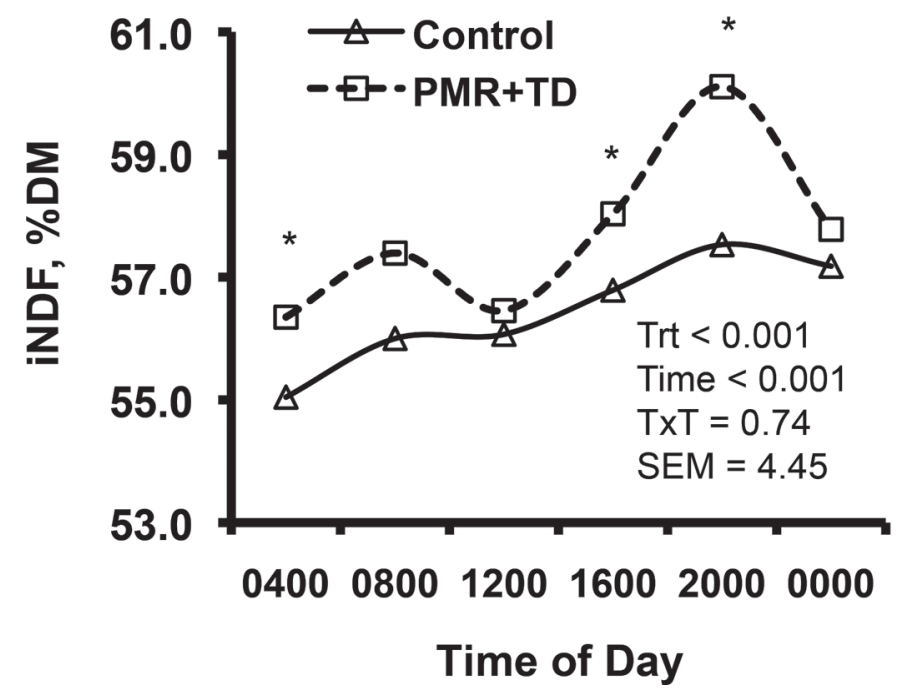

Figure 2. Daily pattern of fecal NDF (panel A) and indigestible NDF (iNDF; panel B) when feeding a TMR (control) or a partial mixed ration plus a top-dress at $0800 \mathrm{~h}(\mathrm{PMR}+\mathrm{TD})$. The grain mix contained steam-flaked, canola meal, and NPN and was fed at $9.5 \%$ of DMI. Effects of treatment (Trt), time, and their interaction $(\mathrm{T} \times \mathrm{T})$, and differences between control and PMR+TD are shown $\left({ }^{*} P<0.05\right.$ and $\left.{ }^{\mathrm{t}} P<0.10\right)$. 
Table 4. Phase (time at peak) and amplitude of a cosine function with a 24 -h period for key variables in lactating cows fed a partial mixed ration plus a top-dress (PMR+TD) or a control TMR ${ }^{1}$

\begin{tabular}{|c|c|c|c|c|c|c|}
\hline \multirow[b]{2}{*}{ Item } & \multicolumn{3}{|c|}{ TMR } & \multicolumn{3}{|c|}{$\mathrm{PMR}+\mathrm{TD}$} \\
\hline & Phase $^{2}$ & $\mathrm{Ampl}^{3}$ & $P$-value ${ }^{4}$ & Phase $^{2}$ & $\mathrm{Ampl}^{3}$ & $P$-value ${ }^{4}$ \\
\hline Fecal NDF, $\%$ of DM & 2042 & 1.9 & $<0.01$ & - & - & 2,042 \\
\hline $\begin{array}{l}\text { Fecal indigestible NDF, } \% \\
\text { of DM }\end{array}$ & - & - & 0.53 & - & - & 0.31 \\
\hline Glucose, $\mathrm{mg} / \mathrm{dL}$ & 0221 & 2.82 & 0.05 & 0240 & 2.29 & $<0.10$ \\
\hline Insulin, $\mu \mathrm{IU} / \mathrm{mL}$ & 1725 & 4.36 & $<0.01$ & $1536^{*}$ & $7.13^{*}$ & $<0.01$ \\
\hline $\mathrm{NEFA},{ }^{5} \mu \mathrm{Eq} / \mathrm{L}$ & - & - & 0.65 & - & - & 0.66 \\
\hline BUN, mg/dL & 1258 & 1.10 & 0.05 & 1234 & $0.95^{*}$ & 0.08 \\
\hline Body temperature, ${ }^{\circ} \mathrm{C}$ & 2047 & 0.197 & $<0.01$ & $2005^{*}$ & $0.292^{*}$ & $<0.01$ \\
\hline
\end{tabular}

${ }^{1}$ Least squares means. Treatments were a TMR-fed control and a partial mixed ration (PMR) plus a top-dress containing steam-flaked corn, canola meal, and NPN at $9.5 \%$ of DMI before feeding the PMR (PMR+TD).

${ }^{2} \mathrm{Phase}$ is time of day at peak.

${ }^{3}$ Amplitude is distance from mesor to peak or trough of cosine model.

${ }^{4}$ Significance of the zero amplitude tests for the cosine fit to each treatment.

${ }^{5} \mathrm{NEFA}=$ nonesterified fatty acids.

*Indicates treatments differ $(P<0.05)$.
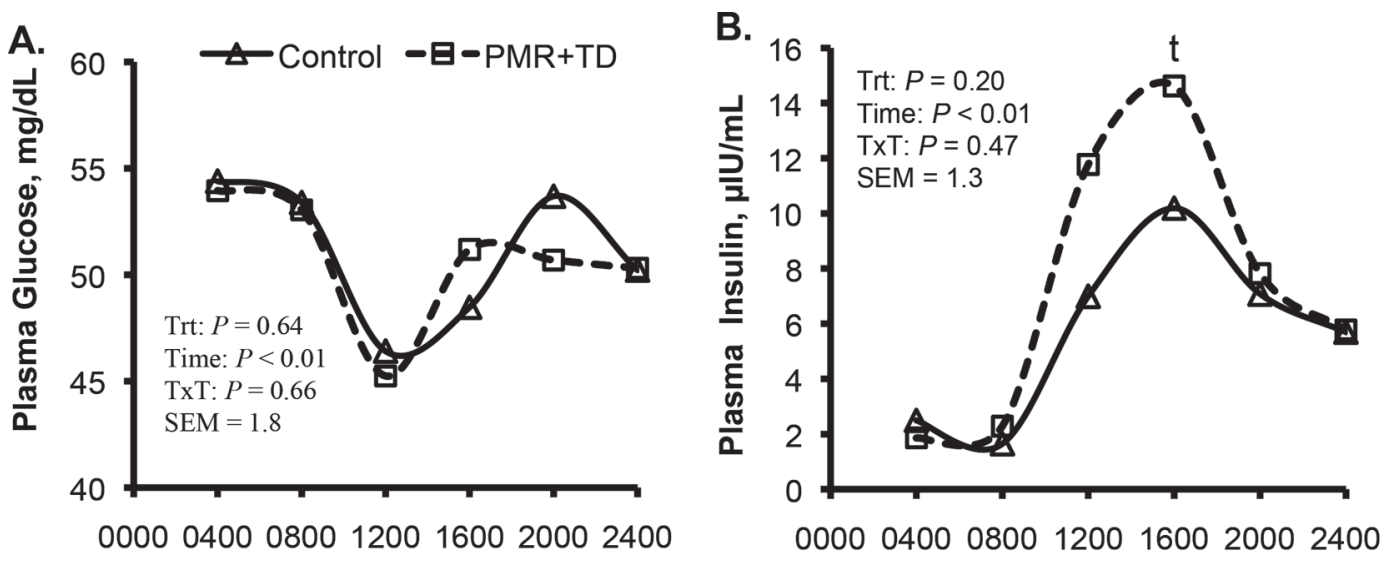

C.
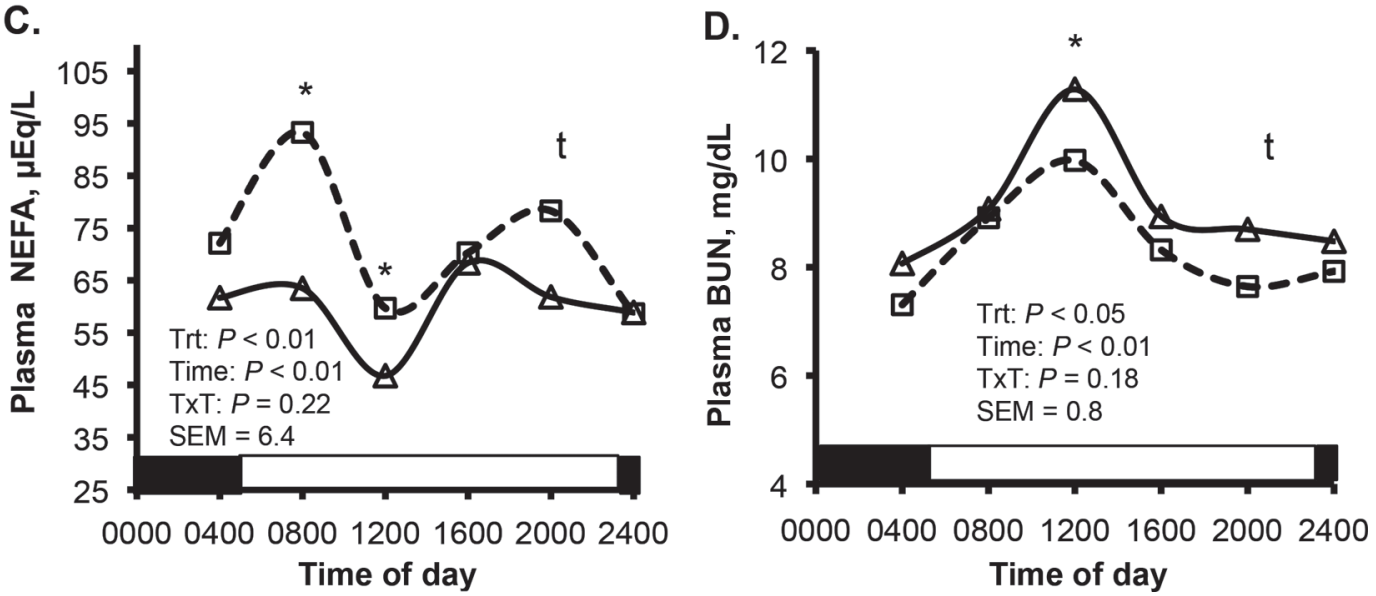

Figure 3. Daily pattern of plasma glucose, insulin, nonesterified fatty acids (NEFA), and BUN when feeding a TMR (control) or a partial mixed ration plus a top-dress at $0800 \mathrm{~h}(\mathrm{PMR}+\mathrm{TD})$. The grain mix contained steam-flaked corn, canola meal, and NPN and was fed at $9.5 \%$ of DMI. Effects of treatment (Trt), time, and their interaction $(\mathrm{T} \times \mathrm{T})$, light and dark phases, and differences between control and PMR+TD are shown $\left({ }^{*} P<0.05\right.$ and $\left.{ }^{\mathrm{t}} P<0.10\right)$. 
production or rumen fill driven by modification of the timing of nutrient intake.

\section{Key Plasma Metabolites and Metabolic Hormones}

Plasma glucose, insulin, and BUN concentration fit a cosine function with a 24 -h period in both treatments, but NEFA did not fit the cosine in either treatment (Table 4). There was no treatment by time interaction by the repeated measures analysis for these variables, although some points differed by the preplanned contrast of the effect of treatment at each time point. Plasma glucose was not different at any time point and no difference was present in amplitude or phase of the cosine function (time at peak; Figure 3). Plasma insulin tended to be higher in PMR+TD at $1600 \mathrm{~h}$ and the cosine amplitude was increased and the phase shifted by PMR+TD (amplitude 7.13 vs. 4.36; Figure 3 ; Table 4). The top-dress is expected to have more rapidly increased rumen starch concentration and the production of propionate after delivery of the mixed rations, resulting in increased insulin stimulation. Interestingly, increased plasma insulin is expected to decrease adipose tissue lipolysis and plasma NEFA, but PMR+TD increased overall NEFA (4.77 vs. 5.67 $\mu \mathrm{IU} / \mathrm{mL}$ ) mainly attributable to increases at 0800 and $1200 \mathrm{~h}$ and a tendency at $2000 \mathrm{~h}$ (Figure 3). It is noteworthy that PMR+TD decreased milk preformed fatty acids whereas plasma NEFA was increased. In cows in positive energy balance, the vast majority of preformed fatty acids come directly from the gut through chylomicrons. The small increase in plasma NEFA appears to have not overcome the effect of insulin on chylomicron metabolism. There was a main effect of treatment on plasma BUN as PMR+TD decreased overall BUN (9.09 vs. $8.35 \mathrm{mg} / \mathrm{dL}$ ), although at individual time points BUN was only decreased at $1200 \mathrm{~h}$ and tended to be decreased at $2000 \mathrm{~h}$. The amplitude of BUN was also decreased by PMR+TD (1.1 vs. $0.95 \mathrm{mg} / \mathrm{dL}$; Table 4). It is not clear if decreased BUN is due to increased microbial growth and decreased ruminal ammonia or decreased AA catabolism due to the anabolic effects of insulin.

\section{Body Temperature}

Core body temperature is highly regulated by the circadian clock in the brain and provides a noninvasive observation of the central clock. Body temperature fit a cosine function with a 24 -h period in both treatments and the phase (time at peak) was delayed $42 \mathrm{~min}$ and the amplitude was increased $0.095^{\circ} \mathrm{C}$ (Table 4; Figure 4). When graphed, the phase delay is clearly seen with PMR+TD nadir occurring at approximately $0900 \mathrm{~h}$ and being generally higher than TMR from 1200 to $2000 \mathrm{~h}$. It is difficult to entrain the central clock through nutritional treatments, but we have previously observed shifts due to feeding time (Niu et al., 2014) and feeding multiple rations over the day (Niu et al., 2017).

\section{CONCLUSIONS}

Starch entry into the rumen is dynamic over the day and is affected by both diet composition and feeding behavior. The high-starch top-dress decreased starch intake during the high intake period of the day, but the extent was limited by the amount of the top-dress. The top-dress increased plasma insulin and slightly decreased milk fat yield, which may indicate partitioning of nutrients away from milk synthesis. This highlights important implications of top-dress supplementation and the timing of supplementation on metabolism that should be considered in the design of top-dressing and robotic feeding strategies. Importantly, the top-dress increased total-tract NDF digestibility and did not increase alternate $\mathrm{BH}$ intermediates, which indicates that subacute ruminal acidosis did not occur. The results demonstrate the potential to develop top-dressing strategies that deliver specific nutrients at desired times to day to modify rumen fermentation, timing of nutrient absorption, or feeding behavior. The effect of top-dresses on feeding behavior specifically requires additional investigation.

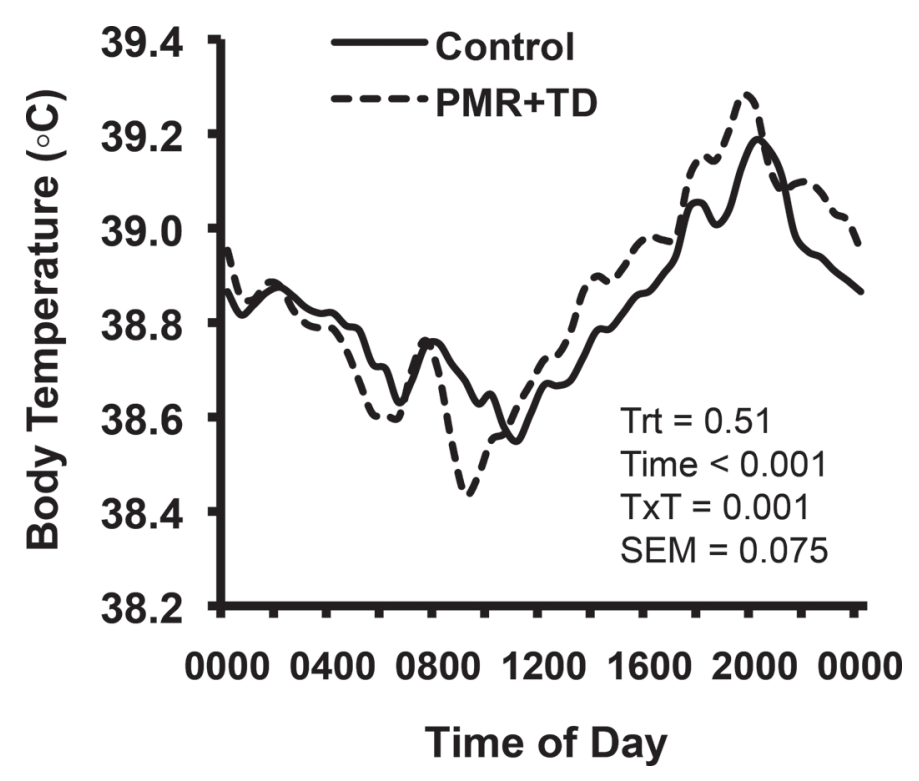

Figure 4. Daily pattern of body temperature when feeding a TMR (control) or a partial mixed ration plus a top-dress at $0800 \mathrm{~h}$ (PMR+TD). The grain mix contained steam-flaked corn, canola meal, and NPN and was fed at 9.5\% of DMI. Effects of treatment (Trt), time, and their interaction $(\mathrm{T} \times \mathrm{T})$ are shown. 


\section{ACKNOWLEDGMENTS}

The authors gratefully acknowledge the technical assistance of Andrew Clarke, Jared Risser, Daniel E. Rico, Liying Ma, Kan Zhou, and Natalie Urrutia (Penn State University, University Park, PA). Gratitude is also expressed to the Pennsylvania State University Dairy Cattle Research and Education Center. Research supported in part by USDA Special Grant 2009-3428120116 (principal investigator Harvatine) and Penn State University.

\section{REFERENCES}

Auldist, M. J., L. C. Marett, J. S. Greenwood, M. M. Wright, M. Hannah, J. L. Jacobs, and W. J. Wales. 2016. Milk production responses to different strategies for feeding supplements to grazing dairy cows. J. Dairy Sci. 99:657-671.

Bach, A., and V. Cabrera. 2017. Robotic milking: Feeding strategies and economic returns. J. Dairy Sci. 100:7720-7728.

Ballou, M. A., R. C. Gomes, S. O. Juchem, and E. J. DePeters. 2009. Effects of dietary supplemental fish oil during the peripartum period on blood metabolites and hepatic fatty acid compositions and total triacylglycerol concentrations of multiparous Holstein cows. J. Dairy Sci. 92:657-669.

DeVries, T. J., M. A. G. von Keyserlingk, and K. A. Beauchemin. 2005. Frequency of feed delivery affects the behavior of lactating dairy cows. J. Dairy Sci. 88:3553-3562.

Fickett, F. M., and M. S. Allen. 2002. Ruminal fluid effects on in vitro digestion kinetics of corn starch. J. Dairy Sci. 85(Suppl. 1):181.

Giannetto, C., and G. Picciano. 2009. Daily rhythms of 25 physiological variables in Bos taurus maintained under natural conditions. J. Appl. Biomed. 7:55-61.
Harvatine, K. J., Y. R. Boisclair, and D. E. Bauman. 2009. Recent advances in the regulation of milk fat synthesis. Animal 3:40-54.

Karkalas, J. 1985. An improved enzymatic method for the determination of native and modified starch. J. Sci. Food Agric. 36:1019 1027.

Lefcourt, A., J. B. Huntington, R. M. Akers, D. L. Wood, and J. Bitman. 1999. Circadian and ultradian rhythms of body temperature and peripheral concentrations of insulin and nitrogen in lactating dairy cows. Domest. Anim. Endocrinol. 16:41-55.

Lefcourt, A. M., J. Bitman, D. L. Wood, and R. M. Akers. 1995. Circadian and ultradian rhythms of peripheral growth hormone concentrations in lactating dairy cows. Domest. Anim. Endocrinol. $12: 247-256$.

Niu, M., Y. Ying, P. A. Bartell, and K. J. Harvatine. 2014. The effects of feeding time on milk production, total-tract digestibility, and daily rhythms of feeding behavior and plasma metabolites and hormones in dairy cows. J. Dairy Sci. 97:7764-7776.

Niu, M., Y. Ying, P. A. Bartell, and K. J. Harvatine. 2017. The effects of feeding rations that differ in fiber and fermentable starch within a day on milk production and the daily rhythm of feed intake and plasma hormones and metabolites in dairy cows. J. Dairy Sci. 100:187-198.

Rico, D. E., and K. J. Harvatine. 2013. Induction of and recovery from milk fat depression occurs progressively in dairy cows switched between diets that differ in fiber and oil concentration. J. Dairy Sci. 96:6621-6630.

Rottman, L. W., Y. Ying, K. Zhou, P. A. Bartell, and K. J. Harvatine. 2014. The daily rhythm of milk synthesis is dependent on the timing of feed intake in dairy cows. Physiol. Rep. 2:e12049.

Schibler, U., J. Ripperger, and S. A. Brown. 2003. Peripheral circadian oscillators in mammals: Time and food. J. Biol. Rhythms $18: 250-260$.

Urrutia, N. L., and K. J. Harvatine. 2017. Acetate dose-dependently stimulates milk fat synthesis in lactating dairy cows. J. Nutr. 147:763-769. 